\title{
REVISED ESTIMATES OF EARTHQUAKE HAZARD IN NEW ZEALAND
}

\author{
W.D. Smith* and K.R. Berryman**
}

\section{SYNOPSIS:}

Earlier estimates of earthquake hazard in New Zealand have been revised by incorporating not only seismological data on known large earthquakes and recent instrumental coverage of small earthquakes but also geological inference from observed ground deformation. The country has been divided into a number of regions, within each of which the density of earthquake occurrence is assumed to be uniform, while rate parameters very from region to region. The effects of earthquakes occurring throughout each region are then obtained by integration. The results are presented in a similar way as in the earlier study. The estimated hazard is slightly reduced for Auckland, Wellington and Christchurch, and significantly increased for Dunedin.

\section{INTRODUCTION:}

Studies of earthquake hazard should ideally be based on both seismological and geological data. Occurrences of large earthquakes are clearly significant, as are the detailed seismological data obtained from instrumental surveillance of small earthquakes. But the time interval from which such data are available is very short in geological terms, and it is therefore prudent to recognize the fact that there are parts of the country where the occurrence of large earthquakes in the Recent geological past can be inferred, but which do not exhibit much activity at present.

The earlier study (Smith, 1978a,b, reported in preliminary form by Smith, 1976) used only the historical seismicity as its data base. The actual locations of large historical earthquakes were used to represent the seismicity, and this is clearly a procedure of limited reliability although it was the best which could be used at the time. The present study takes a different approach, although we retain the formula which was developed in the earlier study to relate the observed intensity, the magnitude of the earthquake, and the locations of the earthquake and the observer.

In the present paper we present only a summary of the new method and results, with a brief discussion of the parameters chosen for the different parts of the country. A full discussion will be given elsewhere.

\section{TECHNIQUE AND PHILOSOPHY:}

We have assumed that earthquake occurrence throughout New Zealand can be represented by a number of regions, in each of which the seismicity is spatially diffuse and uniform. Figure 1 shows the regionalization we have adopted. The boundaries were drawn on the basis of

* Geophysics Division, DSIR, Wellington, New Zealand

**NZ Geclogical Survey, DSIR, Lower Hutt, New Zealand. historical seismicity and geological considerations. Clearly this is an idealization but we claim that the integrated effects of the regionalization are a fair representation of the seismicity. Within each region we assume a law of earthquake occurrence of the form

$$
\begin{array}{rlrl}
\log N & =a-b M_{1}, & M<M_{\max } \\
N & =0 & & M>M_{\max }
\end{array}
$$

where $N$ is the number of earthquakes of magnitude $M$, occurring in any given time, and parameters $a, b$ and $M_{\max }$ vary from region to region. $\mathrm{M}_{\max }$ is the assumed maximum magnitude, and only those earthquakes above some threshold magnitude $\mathrm{M}_{0}$ are considered.

The 1978 study developed a formula for the likely intensity at any site of interest, given the location of the earthquake and its magnitude. Given this formula, the frequency of occurrence of intensity I at any site of interest can be determined by numerical integration over all source regions in which earthquakes can occur, of sufficient magnitude to produce intensity I at the site. The procedure is as follows. It is a generalization of that developed by Cornell (1968), and used for the estimation of earthquake hazard in eastern Canada by Basham, Weichert and Berry (1979).

Write the intensity formula as

$$
I=I \text { (obs, epi, } h, M \text { ) }
$$

where obs is the observer's location epi is the location of the epicentre $h$ is the focal depth $M$ is the magnitude.

This formula can be inverted:

$$
M=M \text { (obs, epi, h, I) }
$$

It may not be possible in practice to invert it explicitly, but a simple iterative computer program can be written which performs the inversion to give the magnitude $M$ which produces intensity $I$ at the observer's location. 


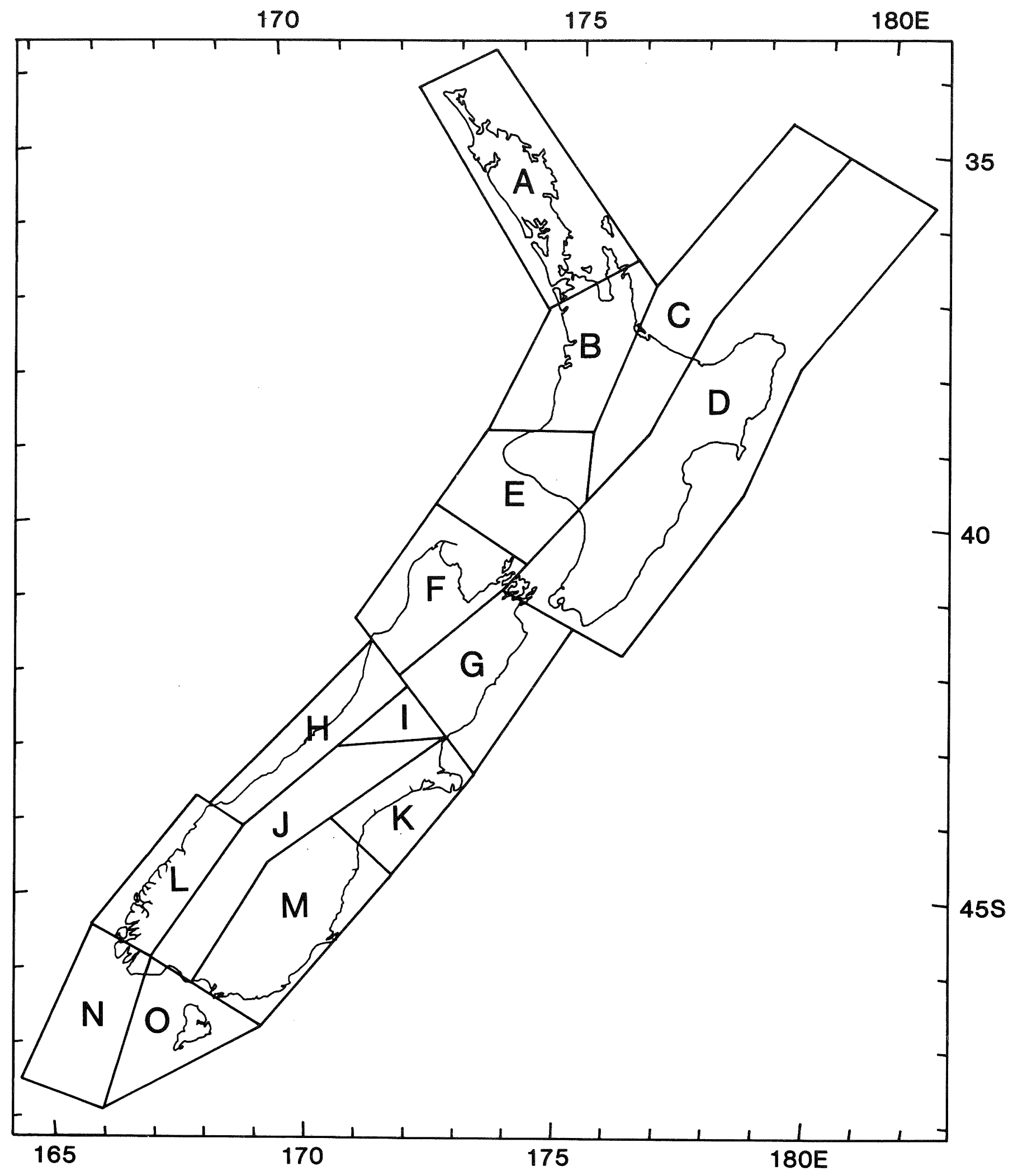

1. Seismicity regions in the model. 
The seismicity model (Equation 1 ) gives the distribution of earthquake magnitude. Integrating this gives the cumulative distribution:

$N=N_{0}\left[10^{b\left(M_{0}-M\right)}-10^{b\left(M_{0}-M_{\max }\right)}\right]$

where $\mathrm{N}_{0}=10^{\mathrm{a}} \log _{10} \mathrm{e} / \mathrm{b}$

$\mathrm{N}_{\mathrm{O}}$ is the total number of earthquakes of magnitude greater than or equal to the threshold, $M_{O^{*}}$ (This assumes that $M_{0}$. and $M_{\max }$ differ by at least two units, an assumption which holds true in practice.)

Parameters $a$ and $b$ are as used in Equation (1). Parameter a does not relate to any particular size of sample. Instead, we here define a parameter a to be the annual number of earthquakes of magnitude 4.0 or greater in an area of $1000 \mathrm{sq} \mathrm{km}$. Thus the annual frequency, per $1000 \mathrm{sq} \mathrm{km}$, of earthquakes of magnitude $M$ or greater is given by

$\mathrm{N}(\mathrm{M})=\mathrm{a}_{4}\left[10^{\mathrm{b}(4-\mathrm{M})}-10^{\mathrm{b}\left(4-\mathrm{M}_{\max }\right)}\right]$

The annual frequency of occurrence of intensity I at a particular site is given by the integral

$N(I)=\int N(M) d x d y$

where $N(M)$ is as in Equation (5) and $M$ is as given in Equation (3). The integration is taken over all source regions in which earthquakes of sufficient magnitude can occur, to cause intensity I or greater at the site. This integration was performed numerically, for a grid of sites $0.5^{\circ}$ apart, and for intensities MM VI to IX at each site.

This procedure overcomes the following deficiencies in the 1978 study.

\section{(i) Length of historical record.}

Seismicity parameter $b$ was assigned for each region from instrumental observations since 1965. Using this value and the historical evidence of large events parameter $a_{4}$ was assigned. If geological evidence suggests that the mean rate of occurrence of large earthquakes is larger than parameters $a_{4}$ and b imply, $a_{4}$ was increased to give a more acceptable rate. In no case was $a_{4}$ increased by more than 100 per cent. In setting this arbitrary limit, we claim to be estimating hazard only for the next 150 years or so, the length of our historical period. Any longer term hazard would be much more difficult to estimate and probably of much less practical use, because for most areas of human endeavour only short-term estimates of hazard are relevant. Parameter M max' the assumed maximum magnitude for each particular region, was chosen with an eye to both the seismological and geological records. The choice of appropriate values is admittedly somewhat subjective, but we claim that it is realistic.

Deficiency of the historical record.

Adjustment of parameter $a_{4}$ met

this objection. In the Bay of Plenty/East Cape region, for instance, the seismicity regions $\mathrm{C}$ and $\mathrm{D}$ were extended northeastwards with the same seismicity parameters as further south, to provide more realistic estimates of the hazard near the coast (Fig. I). The same was done with the seismicity model of the deep earthquakes. The regions were extended only to a point where a further extension would not significantly affect the computed frequencies of occurrence on land.

(iii) Distribution of intensities at individual sites.

In the 1978 study it was assumed that the distribution of intensities at any given site is exponential. In the present study it was not necessary to make any assumption about the form of the intensity distribution. Frequencies of occurrence were computed for each intensity level, using the seismicity model and the attenuation formula. The 1978 study, in assuming an exponential distribution of intensities at each site, effectively assumed an infinite maximum magnitude. Because it was no longer necessary to assume a form for the distribution of intensities, the physically realistic assumption of a finite maximum magnitude in each region could be accommodated without difficulty.

(iv) The effects of deep earthquakes.

The 1978 study accounted for only the shallow seismicity. By setting up the seismicity model in terms of a number of discrete regions, it has been possible to add further regions to quantify the deep earthquake activity. The intensity formula as originally defined in the 1978 study included focal depth as a parameter. Including the deep activity in the calculations has the effect of increasing the frequencies of occurrence of the low intensities. It has no effect for MM VIII and higher.

\section{THE SEISMICITY MODEL}

The regions in Figure 1 were chosen to be (i) simple in shape and (ii) adequately taking into account the regional variations in seismicity and geology. Peek, Berrill and Davis (1981) presented a model which is similar in concept, but includes smooth transitions between regions, which are much more complicated in shape than shown here. We do not consider that the complicated shapes in the Peak et al model are justified, nor is the smooth transition. Some of the tectonic boundaries are well defined, and regional boundaries can be identified with these. An argument for simplicity in modelling is also that the attenuation function (Equation 2) will smooth out the effects of the boundaries anyway, when the hazard is evaluated in terms of ground motion, although it is recognised that this principle applies more at low 
intensities than at high intensities, for the latter must result from a large earthquake nearby.

Details of the model are given in Table 1. For each region we list the area and the parameters $b$ and $M$ followed by numbers of earthquameax and derived values of $a_{4}$, for each of three time periods and magnitude thresholds: magnitudes greater than or equal to 4.0 since $1965,5.0$ since 1942 and 6.5 since 1840. The 1840 date represents the beginning of the period of significant European population throughout the country. There was an increase in the number of seismographs deployed from about 1942 and again from about 1965. The adopted value of $a_{4}$ is given in the final column of Table 1 .

The b-values are determined from the instrumental record since 1965. The method of maximum likelihood (e.g. Aki 1965) was used to calculate $b$ and its standard error, but these figures were not used directly because it has been reported (Smith 1981) that b can change significantly in time, when calculated for small regions. It was therefore appropriate to calculate $b$ for each region using a time-windowing technique, and for a long-term estimate to choose an'appropriate background level, unaffected by short-lived periods of high b-value. The b-values were chosen with a view to having no large differences from one region to the next, except where boundaries are obvious tectonic ones. No standard errors are presented, because the chosen values were not determined by the formal procedure.

Many of the large historical earthquakes have been given very approximate locations, often close to the boundaries between regions in Figure 1. Often the magnitude is very uncertain also. Many of these events were assigned magnitude class B by Eiby (1968), implying the range 6.0 to 7.5 . Each of these has been assigned an epicentre and magnitude from considerations of their felt effects, and comparing with the curves for intensity as a function of magnitude and distance obtained by Smith (1978a). Those of magnitude 6.5 and greater are 1 isted in Table 2 and shown in Figure 2. These are preliminary revisions only. A definite list will be published elsewhere, but the magnitudes are not expected to differ significantly from those listed. In some cases earlier estimates by other workers have been retained. Proper acknowledgement of these will be given elsewhere with the full discussion of the present study.

The known active faults are shown in Figure 3. Their locations, displacements and inferred recurrence intervals of faulting provided constraints on the regionalization and the definition of parameters in the seismicity model. Maximum magnitudes have been set at 8.5 throughout the regions of current high seismicity and 8.0 elsewhere, except that the figure 7.5 is adopted in Northland, the Taupo-Bay of Plenty zone, and for deep earthquakes (see below).

The full presentation of this study, at present in preparation, will give a region-by-region discussion of the reasons for the choice of the particular parameters. In each case we have considered the three estimates of rate of occurrence listed in Table 1. The choice of a representative rate from among these three values and the geological characteristics rested on consideration of the particular character of each region.

Figure 4 shows the deep earthquake region in the model. Foci are confined to a plane, which dips northwestwards. The minimum depth is thus along the southeastern boundary of the region, and is chosen to be $82 \mathrm{~km}$ for conformity with the intensity model for deep earthquakes (Smith 1978a). Parameter $a_{4}$ is a

function of depth and latitude. A quadratic function of depth was found to be appropriate, equal to zero at $h=82$ and at the north-western boundary of the region. The depth of this boundary is given by

$h_{\max }=273+30(38-1 \mathrm{at})$

and the expression for $a_{4}$ is

$a_{4}=0.92(186+55(38-1 a t))$

$$
(h-82)\left(h_{\max }-h\right)
$$

$$
\left(h_{\max }-82\right)^{2}
$$

with no increase north of $38^{\circ} \mathrm{s}$. adequately models the variation of seismicity with depth and with latitude, although possibly overestimates the rate of activity north of $38^{\circ} \mathrm{S}$. This has little effect on intensities on land greater than MM VI. The h-value used is 1.0 , and the maximum magnitude 7.5. Gibowicz (1974) found a variation of $b$ with depth but the difference between his model and this simpler one is not significant for hazard purposes.

\section{TWO RECENT STUDIES}

A bibliography of studies relevant to the quantification of earthquake hazard in New Zealand is given by Smith (1982). Of these, two studies in particular warrant brief comment here.

Matuschka (1980) developed formulae for peak acceleration and Modified Mercalli intensity as functions of magnitude, and used them with the catalogue of New Zealand earthquakes to produce contour maps of the frequency of occurrence of damaging ground motions, expressed as peak acceleration, peak velocity and Modified Mercalli intensity. He also modelled the seismicity in somewhat the same way as has been done in this study, and prepared further maps for comparison. In addition, he examined spectral characteristics of likely ground motion at Wellington as a case study.

We contend, however, that although 

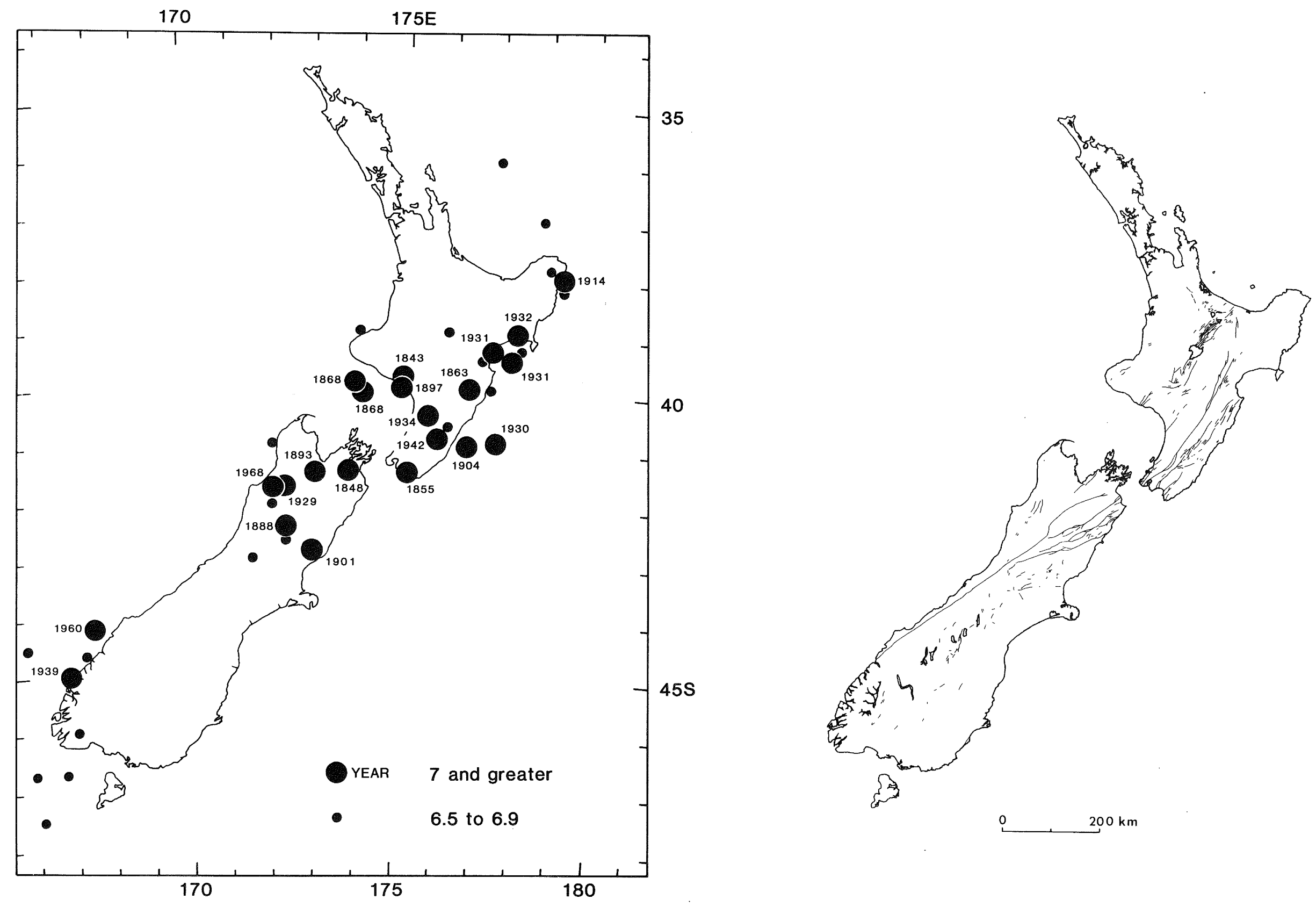

2. Epicentres of shallow earthquakes of magnitude 6.5 and greater since 
his study was valuable, there are certain areas in which it could have been improved. In particular, the attenuation relationship he used took no account of the systematic variation throughout New zealand of the dependence of intensity on magnitude and distance. This was quantified by Smith (1978a), but was first reported by Hayes (1936). Matuschka claims that he could not resolve it, except for anomalies in the Fiordland region. incorporating this feature leads to significant variation in the hazard levels calculated, and we claim that a more careful analysis would have resolved it.

Matuschka's seismicity model represents only the activity from 1940 to 1976, so it does not include the active period of the early 1930's. His b-values are so low that they imply deficiencies in the earthquake catalogue at the low magnitude end, but he does not seem to be aware of this. Although there was instrumental coverage in New Zealand throughout the period he used, it was clearly inadequate to detect all events down to his magnitude threshold of 4.5. And while he used an established procedure to calculate seismicity parameters $a$ and $b$, Smith (1981) has shown that within small regions there can be significant changes in these parameters, particularly b, over periods of a decade or so. Rigorous statistical evaluation of $a$ and $b$ may not therefore be appropriate, if what is needed is the background level. This comment is not made as a criticism of his work, but rather as an indication of some more recent work which has a bearing on the problem.

The purpose of regionalization is to include tectonic and geological information, which Matuschka does not seem to have done as fully as he could have. Tectonic considerations affect his choice of maximum credible earthquake and the regionalization itself, but are not reflected in the seismicity rates.

Matuschka is critical of the accepted procedures used for constructing isoseismal maps, and of the procedures used in the 1978 study for developing a formula for the likely intensity, but his criticisms are partly due to a misunderstanding of the procedures, or of the techniques used in that study. While we agree that if estimates of peak velocity or acceleration are required, it is better to estimate them directly rather than via an intensity formula. The fact that there is an order of magnitude more intensity data than accelerograms should not be lost sight of. This situation is not likely to change, no matter how many recorders are installed. Further, intensity data are derivable from historical records of large earthquakes, which do not occur often and are therefore important when they do. The effects of earthquakes are so complex that all available data should be used, no just those that are the most convenient. Intensity estimates are not easy to accommodate in building regulations, and are the subject of traditional objection by engineers, but while peak acceleration is a convenient parameter, Housner (1981) has commented that it does not characterize the ground motion well at all. The convenient procedure is not always the best. Matuschka's efforts to estimate the spectral content of ground motion at a specific site are therefore much more valuable.

Peek (1980) adopted a similar procedure for evaluating the seismicity as has been used here, in that he regionalized the country and assigned seismicity parameters to each region. His results were presented in terms of spectral accelerations, in detail at two sites and also in a contour map. His definition of the parameters of the model, however, drew on rates of deformation as well as historical seismicity. He also used a technique which estimated the seismic moment, based on tectonic shear rates.

Our chief objection to the study is the reliability he seems to place on the calculation procedures he uses. The seismic moment calculation, for instance, is useful only as a guide, and is not as reliable as is suggested by the number of significant figures he presents. This is because there are a number of assumptions which have very little basis in observation, but rather are derived from a postulated model of tectonic movement and earthquake generation.

His choice of boundaries in his regionalization is somewhat unusual, with fine detail rather difficult to justify. A novel approach was to use "fuzzy boundaries" as a continuous variation in seismicity level from one region to the next. While this may be elegant it is hardly justified because the attenuation function itself will provide smoothing, except at very high levels of ground motion. Further, there are places where the tectonic boundaries are rather well defined, and to introduce fuzzy boundaries there is inappropriate.

The estimation of a maximum magnitude for each region would have improved the study, as would the inclusion of the effects of deep earthquakes. Further limitations are imposed by his a priori assumptions about the form of his attenuation model, and, as with Matuschka's work, the lack of regional variations in this. There is clearly a need (and Peek recognizes this) for further studies of the attenuation of strong ground motion in New Zealand.

\section{COMPUTED HAZARD ESTIMATES}

Figures 5 to 8 show contour maps of mean return period for Modified Mercalli intensities MM VI to IX. such they constitute revisions of Figures 8 to 11 in Smith (1978b). are given in Table 3 .

An important difference between the new results and those of the 1970 study is the level of hazard assigned 


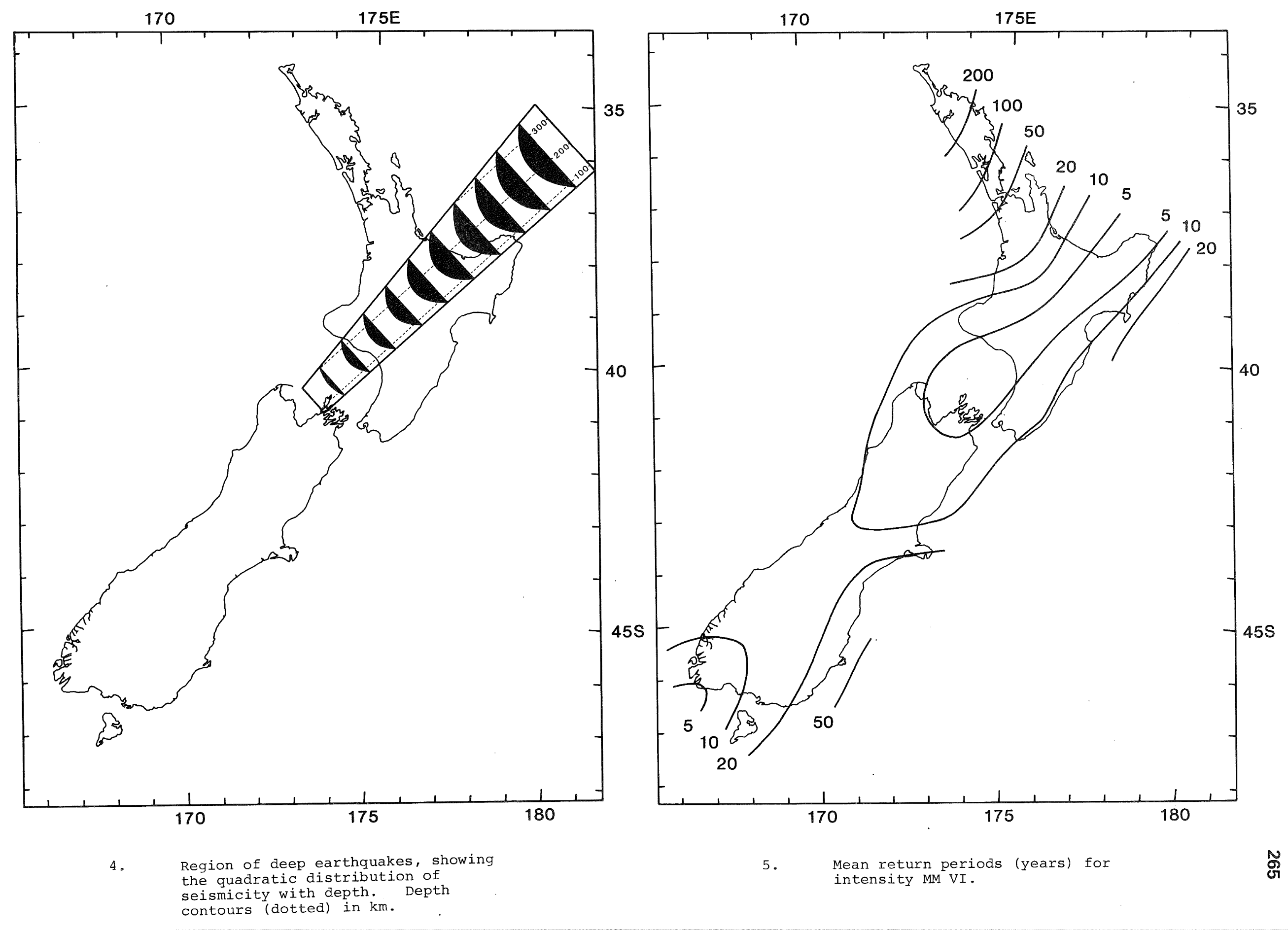




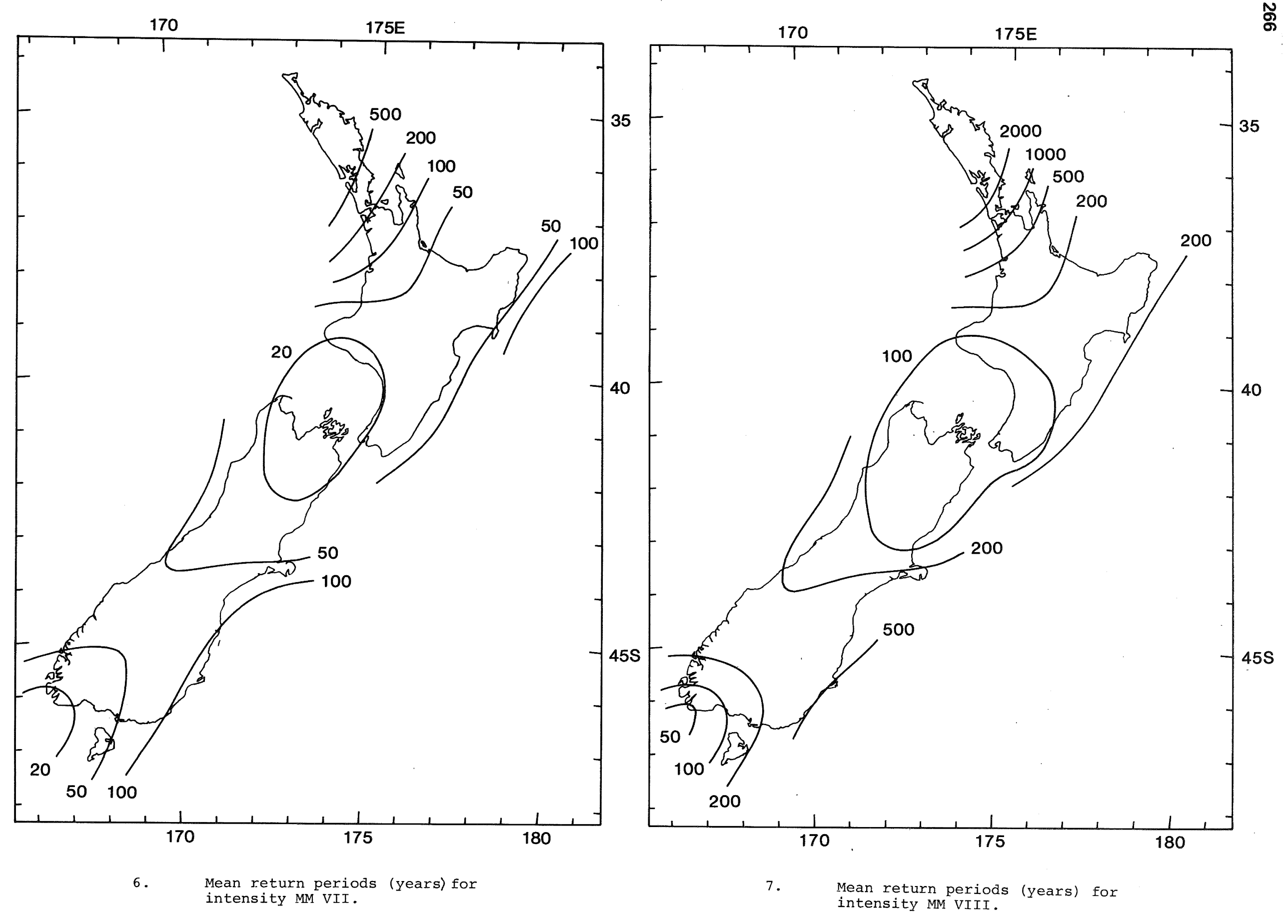


to the East Cape Peninsula. Because the seismic regions $C$ and $D$ (Figure 1 ) were extended north-eastwards, and because the 1978 study used only the catalogue of large earthquakes, which may well be deficient in this region in early years, the calculated level of hazard has increased to a figure more compatible with that indicated from geological considerations.

The generally long return periods in the Fiordland area are a consequence of the low intensities which are observed there, as noted in the 1978 study.

There is little change from the 1978 estimates for the centre of the country from Hawke's Bay to Banks Peninsula. For the less seismic areas such as Northland and Otago, however, the new estimates of the mean return periods for low intensities are rather shorter than in the 1978 study. This is because the seismicity level in the model was increased from the historical figure on geological grounds. For high intensities in these areas the mean return period has increased. This may be because of the maximum magnitude limits imposed.

Figure 9 and 10 show the intensities with probabilities of occurrence within 50 years of five and ten percent respectively. This is probably a more useful way to express the results than as in Figures 5 to 8 , because it refers to ground motion levels with equal probability throughout the country. Figure 9 should be compared with Figure 13 in Smith (1978b). The MM $X$ region in the middle of the country in Figure 9 calls for comment. In fact the hazard estimate barely reached $M M \mathrm{X}$ in this region, and was only just less than MM $x$ for much of the East Coast of the North Island. The region of highest risk is therefore not as centralised as Figure 9 might suggest.

Table 3 shows return periods for a selection of localities, and can be compared with Table 2 of Smith (1978b). It gives more detail concerning the effects of increased seismicity levels imposed, in particular at Auckland and Dunedin. In the 1978 study it was assumed that return periods for successive $\mathrm{MM}$ intensity levels form a geometric progression, and that this assumption was not made in the present study. Departures from a geometric progression, apparent in Table 3, show that this assumption led to unduly low return periods for high intensities at some localities. Figure 11 shows the variation of return period with intensity at Auckland, Wellington and Christchurch, with the 1978 results also displayed.

An important aspect of hazard which has not been touched on in the present study is that of microzoning, the variation in ground motion throughout a small area, due to differences in subsoil, geological structure, topography, etc. The results of the present study refer to average ground conditions, and have been computed on a regional basis. They should be modified in any area of unduly poor, or especially firm, ground conditions. The modelling of microzoning effects is an area which needs much more study.

The regional character of the whole study should also be recognized, and its shortcomings appreciated. While we have assumed that the seismicity level is uniform throughout each region, and have calculated the hazard accordingly, it is clear that fine detail in the hazard maps could only have been produced by the choice of smaller regions. The regions chosen were, in fact, as large as could more or less satisfactorily represent both the seismicity and geology, while remaining relatively simple. A more refined study might have subdivided the regions, and a case in point is the Dunedin area, close to the extension of the line of the active Akatore Fault which probably ruptured about 900 years ago and 1600 years ago, and is thought to be the most currently active fault in this region. It may therefore be that this part of Region $M$ has experienced high intensities more often in Recent times than Table 3 suggests.

\section{TOWARDS NEW ZONING CRITERIA}

This study was done as part of the work of the Relative Earthquake Risk Subcommittee of the Standards Association of New Zealand. It is intended that further work will estimate ground motion in parameters of more direct use to engineers (velocity, acceleration, etc.) in order to present recommendations on relative risk to the Loadings Code Amendments Committee. Much of the work of Matuschka (1980) and Peek (1980) is relevant to this, as is that of Mulholland (1982). The chief problem remains that of the selection of an appropriate attenuation function which expresses ground motion in terms of parameters which can be used in design, at the same time reflecting the observed characteristics of New Zealand earthquakes. Figure 10 is one which may prove useful for zoning, in that it defines a few rather simple zones.

\section{ACKNOWLEDGEMENTS :}

The study began as a joint project between the first author (WDS) and Mr G.J. Lensen, whose contributions are gratefully acknowledged. The second author (KRB) provided the geological input after Mr Lensen's retirement. Numerous other colleagues at Geophysics Division and Geological survey have made critical comments and suggestions on the text.

\section{REFERENCES :}

Aki, K. 1965: Maximum likelihood estimate of $b$ in the formula $\log N=a-b M$ and its confidence limits. Bulletin of the Earthquake Research Institute of Tokyo University 43: 237-239.

Basham, P.W.; Weichert, D.H.; Berry, M.J. 1979: Regional assessment of seismic risk in eastern Canada. Bulletin of the Seismological Society of America 69: 1567-1602. 

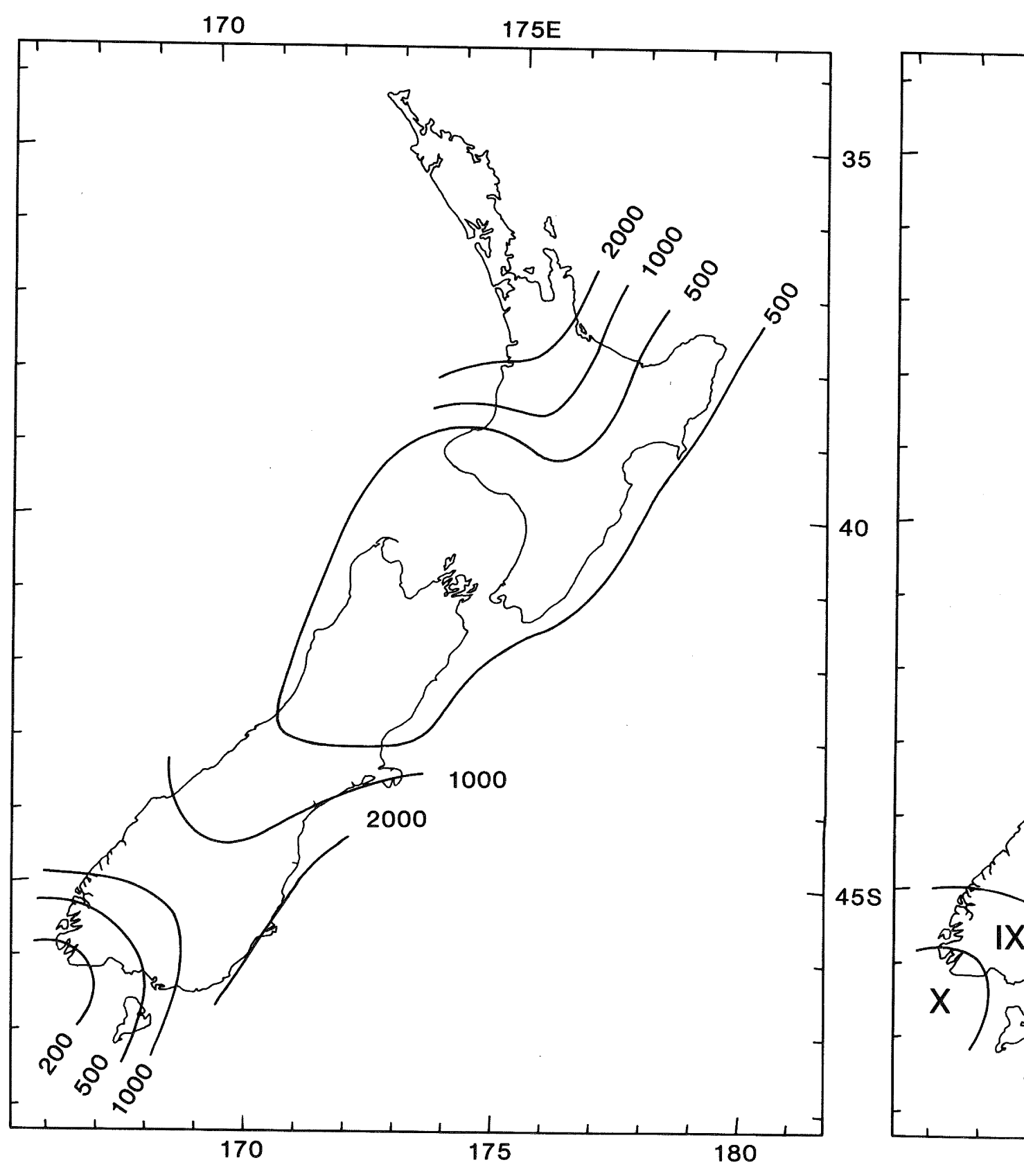

170

$175 \mathrm{E}$

8. Mean return periods (years) for intensity MM IX. 9. Intensities with a $5 \%$ probability
of occurrence within 50 years. 


\begin{tabular}{|c|c|c|c|c|c|c|c|c|c|c|}
\hline \multirow[b]{2}{*}{ Region } & \multirow{2}{*}{$\begin{array}{l}\text { area } \\
\text { sq km }\end{array}$} & \multirow[b]{2}{*}{ b } & \multirow[b]{2}{*}{$M_{\max }$} & \multicolumn{2}{|c|}{$1965-82$} & \multicolumn{2}{|c|}{$1942-82$} & \multicolumn{2}{|c|}{$1840-1982$} & \multirow{2}{*}{$\begin{array}{c}a_{4} \\
\text { chosen }\end{array}$} \\
\hline & & & & $N_{4}$ & $a_{4}$ & $\mathrm{~N}_{5}$ & $a_{4}$ & N6.5 & $a_{4}$ & \\
\hline A & 54028 & 1.2 & 7.5 & 3 & 0.003 & 4. & 0.029 & 0 & & 0.03 \\
\hline B & 34288 & 1.2 & 8.0 & 36 & 0.058 & 5 & 0.056 & 0 & & 0.10 \\
\hline c & 23224 & 1.2 & 7.5 & 185 & 0.443 & 21 & 0.350 & 1 & 0.321 & 0.45 \\
\hline D & 89867 & 1.13 & 8.5 & 687 & 0.125 & 159 & 0.582 & 16 & 0.837 & 0.85 \\
\hline $\mathbf{E}$ & 31428 & 1.15 & 8.5 & 1.48 & 0.262 & 22 & 0.241 & 5 & 0.838 & 0.80 \\
\hline$F$ & $31: 460$ & 1.13 & 8.5 & 280 & 0.495 & 29 & 0.304 & 5 & 0.746 & 0.70 \\
\hline G & 35434 & 1.1 & 8.5 & 154 & 0.242 & 43 & 0.373 & 4 & 0.447 & 0.60 \\
\hline H & 24366 & 1.05 & 8.5 & 45 & 0.102 & 12 & 0.135 & 0 & & 0.20 \\
\hline I & 6793 & 1.1 & 8.5 & $19^{\circ}$ & 0.156 & 7 & 0.317 & 1 & 0.583 & 0.40 \\
\hline $\mathbf{J}$ & 30824 & 1.1 & 8.0 & 41 & 0.074 & 11 & 0.110 & 0 & & 0.11 \\
\hline $\mathbf{R}$ & 19368 & 1.1 & 8.0 & 10 & 0.029 & 2 & 0.032 & 0 & & 0.03 \\
\hline L & 26500 & 0.95 & 8.5 & 316 & 0.662 & 78 & 0.640 & 4 & 0.253 & 0.70 \\
\hline$M$ & 43971 & 1.1 & 8.0 & 16 & 0.020 & 6 & 0.042 & 0 & & 0.08 \\
\hline $\mathbf{N}$ & 31931 & 1.0 & 8.5 & 296 & 0.515 & 40 & 0.306 & 5 & 0.350 & 0.60 \\
\hline 0 & 19304 & 1.1 & 8.0 & 8 & 0.023 & 5 & 0.080 & 0 & & 0.08 \\
\hline
\end{tabular}

TABLE 1: Parameters for the seismicity regions of Figure 1. Data for Regions C and D refer only to the parts of these regions south of East Cape.

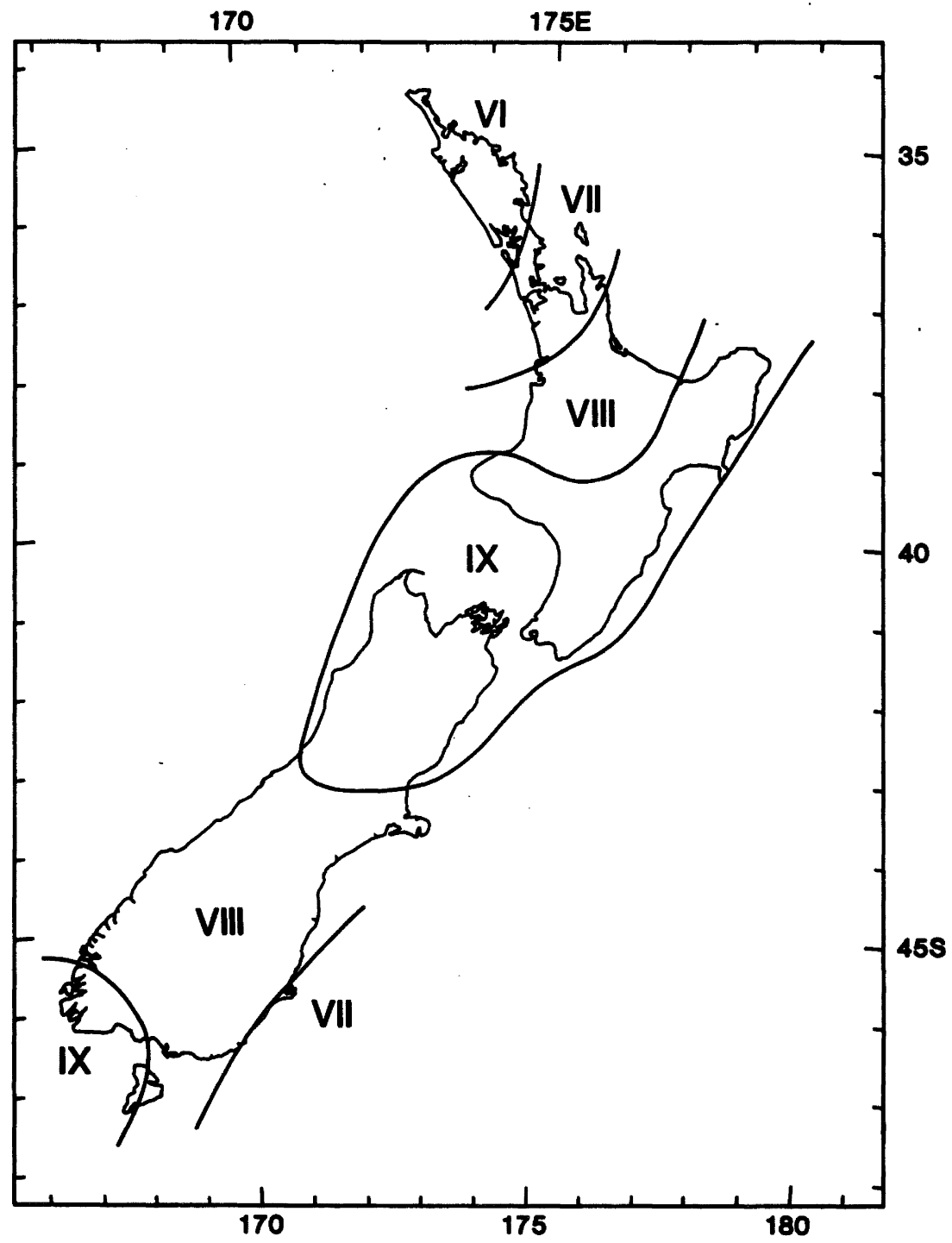

10. Intensities with a 108 probability of occurrence within 50 years. 
Cornell, C.A. 1968: Engineering seismic risk analysis. Bulletin of the Seismological Society of America 58: 1583-1606.

Eiby, G.A. 1968: An annotated list of New Zealand earthquakes. N.Z. Journal of Geology and Geophysics 11: 630-647.

Gibowicz, S.J. 1974: Frequency-magnitude, depth and time relations for earthquakes in an island arc: North Island, New Zealand. Tectonophysics 23: 283-297.

Hayes, R.C. 1936: Intensity distribution in New Zealand earthquakes. N.Z. Journal of Science and Technology XVIII, 508-511.

Housner, G.W. 1981: What we should know about strong earthquakes, past and present. Invited address, IASPEI/IAEE symposium, London, Ontario.

Matuschka, T. 1980: Assessment of seismic hazards in New Zealand. University of Auckland, Dept of Civil Engineering, Report No. 222.

Mulholland, W.M. 1982: Estimation of design earthquake motions for New Zealand. University of Canterbury, Department of Civil Engineering, Report $82 / 9$.

Peak, R. 1980: Estimation of seismic risk for New Zealand. University of Canterbury, Department of Civil Engineering, Report 80/21.

Peek, R.,; Berrill, J.B.; Davis R.D.; 1980: A seismicity model for New Zealand. Bulletin of the N.Z. National Society for Earthquake Engineering 13: 355-364.

Smith, W.D., 1976: Statistical estimates of the likelihood of earthquake shaking throughout New Zealand. Bulletin of the N.Z. National Society for

Earthquake Engineering 9: 213-221.

Smith, W.D. 1978a: Spatial distribution of felt intensities for New Zealand earthquakes. N.Z. Journal of Geology and Geophysics 21: 293-311.

Smith, W.D. 1978b: Earthquake risk in New Zealand: statistical estimates. N.Z. Journal of Geology and Geophysics 21: $313-327$.

Smith, W.D. 1981: The b-value as an earthquake precursor. Nature 289: 136139 .

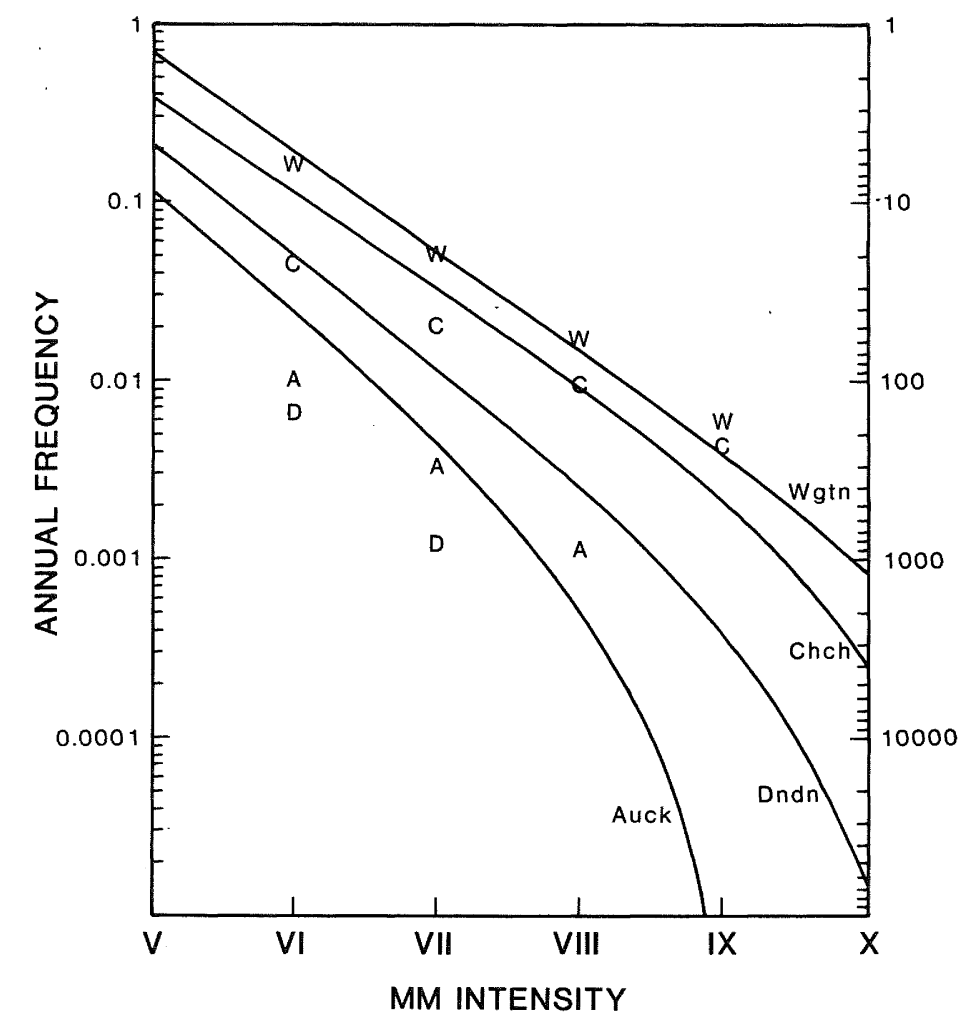

Smith, W.D. 1902: Pitfalls in the estimation of seismic hazard, Bulletin of the N.Z. National Society for Earthquake Engineering 15: 77-81. 


\begin{tabular}{|c|c|c|c|c|c|}
\hline & Date & & tion & Mag. & Region \\
\hline $\begin{array}{l}1843 \\
1846 \\
1848 \\
1853 \\
1855\end{array}$ & $\begin{array}{ll}\text { Jul } & 8 \\
\text { Nov } & 18 \\
\text { Oct } & 15 \\
\text { Jan } & 1 \\
\text { Jan } & 23\end{array}$ & $\begin{array}{l}39.9 \\
41 \\
41.5 \\
39.0 \\
41.5\end{array}$ & $\begin{array}{l}175.0 \\
172 \\
173.8 \\
174.0 \\
175.2\end{array}$ & $\begin{array}{l}7.5 \\
6.5 \\
7.1 \\
6.8 \\
8.0\end{array}$ & $\begin{array}{l}E \\
F \\
G \\
E \\
D\end{array}$ \\
\hline $\begin{array}{l}1863 \\
1868 \\
1881 \\
1880\end{array}$ & $\begin{array}{ll}\text { Feb } & 22 \\
\text { Aug } & 16 \\
\text { Oct } & 18 \\
\text { Dec } & 4 \\
\text { Aug } & 31\end{array}$ & $\begin{array}{l}40.0 \\
40 \\
40 \\
42.6 \\
42.6\end{array}$ & $\begin{array}{l}176.5 \\
174 \\
174 \\
172.3 \\
172.3\end{array}$ & $\begin{array}{l}7.5 \\
7.2 \\
7.0 \\
6.8 \\
7.3\end{array}$ & $\begin{array}{l}D \\
E \\
E \\
G \\
G\end{array}$ \\
\hline $\begin{array}{l}1893 \\
1895 \\
1897 \\
1901 \\
1904\end{array}$ & $\begin{array}{ll}\text { Feb } & 11 \\
\text { Aug } & 18 \\
\text { Dec } & 7 \\
\text { Nov } & 16 \\
\text { Aug } & 8\end{array}$ & $\begin{array}{l}41.5 \\
39 \\
40 \\
43 \\
41\end{array}$ & $\begin{array}{l}173 \\
176 \\
175 \\
173 \\
176.5\end{array}$ & $\begin{array}{l}7.2 \\
6.5 \\
7.0 \\
7.0 \\
7.5\end{array}$ & $\begin{array}{l}F \\
C \\
E \\
G \\
D\end{array}$ \\
\hline $\begin{array}{l}1911 \\
1914 \\
1917 \\
1918\end{array}$ & $\begin{array}{ll}\text { Oct } & 5 \\
\text { Oct } & 6 \\
\text { Oct } & 28 \\
\text { Aug } & 5 \\
\text { Nov } & 3\end{array}$ & $\begin{array}{l}39.5 \\
38 \\
38 \\
40.8 \\
47\end{array}$ & $\begin{array}{l}177 \\
178.5 \\
178.5 \\
176.0 \\
165\end{array}$ & $\begin{array}{l}6.5 \\
7.5 \\
6.5 \\
6.5 \\
6.8\end{array}$ & $\begin{array}{l}D \\
D \\
D \\
D \\
N\end{array}$ \\
\hline $\begin{array}{r}1929 \\
1930 \\
1931\end{array}$ & $\begin{array}{ll}\text { Mar } & 9 \\
\text { Jun } & 16 \\
\text { Jun } & 22 \\
\text { Feb } & 12 \\
\text { Feb } & 2\end{array}$ & $\begin{array}{l}43 \\
41.7 \\
42 \\
40.9 \\
39.3\end{array}$ & $\begin{array}{l}171.5 \\
172.2 \\
172 \\
177.1 \\
177.0\end{array}$ & $\begin{array}{l}6.9 \\
7.6 \\
6.5 \\
7.0 \\
7.8\end{array}$ & $\begin{array}{l}F \\
F \\
F \\
D \\
D\end{array}$ \\
\hline $\begin{array}{l}1931 \\
\\
1932 \\
1934\end{array}$ & $\begin{array}{ll}\text { Feb } & 8 \\
\text { Feb } & 13 \\
\text { Sep } & 21 \\
\text { Sep } & 15 \\
\text { Mar } & 5\end{array}$ & $\begin{array}{l}39.2 \\
39.5 \\
37.0 \\
38.9 \\
40.5\end{array}$ & $\begin{array}{l}177.5 \\
177.5 \\
178.0 \\
177.55 \\
175.6\end{array}$ & $\begin{array}{l}6.5 \\
7.1 \\
6.8 \\
7 \\
7.5\end{array}$ & $\begin{array}{l}D \\
D \\
D \\
D \\
D\end{array}$ \\
\hline $\begin{array}{l}1938 \\
1939 \\
1942 \\
1943\end{array}$ & $\begin{array}{ll}\text { Dec } & 15 \\
\text { Feb } & 10 \\
\text { Jun } & 24 \\
\text { Aug } & 2 \\
\text { Sep } & 22\end{array}$ & $\begin{array}{l}40 \\
45 \\
40.9 \\
46.1 \\
36\end{array}$ & $\begin{array}{l}177 \\
167 \\
175.9 \\
167.0 \\
177\end{array}$ & $\begin{array}{l}6.6 \\
7 \\
7.0 \\
6.7 \\
6.8\end{array}$ & $\begin{array}{l}D \\
L \\
D \\
N \\
C\end{array}$ \\
\hline $\begin{array}{l}1945 \\
1951 \\
1957 \\
1960 \\
1968\end{array}$ & $\begin{array}{ll}\text { Sep } & 1 \\
\text { Apr } & 23 \\
\text { Dec } & 31 \\
\text { May } & 24 \\
\text { May } & 23\end{array}$ & $\begin{array}{l}47.47 \\
37.8 \\
44.5 \\
44.2 \\
41.77\end{array}$ & $\begin{array}{l}166.12 \\
178.2 \\
166.0 \\
167.7 \\
172.01\end{array}$ & $\begin{array}{l}6.5 \\
6.7 \\
6.6 \\
7.0 \\
7.1\end{array}$ & $\begin{array}{l}N \\
D \\
L \\
L \\
F\end{array}$ \\
\hline $\begin{array}{l}1968 \\
1976 \\
1979\end{array}$ & $\begin{array}{ll}\text { Sep } & 25 \\
\text { May } & 4 \\
\text { Oct } & 12\end{array}$ & $\begin{array}{l}46.71 \\
44.67 \\
46.70\end{array}$ & $\begin{array}{l}166.78 \\
167.38 \\
166.03\end{array}$ & $\begin{array}{l}6.5 \\
6.5 \\
6.5\end{array}$ & $\begin{array}{l}\mathrm{N} \\
\mathrm{L} \\
\mathrm{N}\end{array}$ \\
\hline
\end{tabular}

TABLE 2: Earthquakes of magnitude 6.5 or greater from 1840 to 1982. 


\begin{tabular}{|c|c|c|c|c|}
\hline & MM VI & VII & VIII & IX \\
\hline Kaitaia. & 240 & 980 & & \\
\hline Whangarei & 160 & 760 & & \\
\hline Auckland & 62 & 260 & 1400 & \\
\hline Tauranga & 12 & 50 & 210 & 1200 \\
\hline Hamilton & 24 & 96 & 420 & 2500 \\
\hline Whakatane & 5 & 32 & 130 & 490 \\
\hline Rotorua & 8 & 45 & 190 & 1000 \\
\hline Taupo & 5 & 41 & 180 & 900 \\
\hline New Plymouth & 8 & 29 & 110 & 400 \\
\hline Napier/Hastings & 8 & 42 & 140 & 430 \\
\hline Wanganui & 4 & 17 & 72 & 270 \\
\hline Palmerston North & 5 & 23 & 71 & 210 \\
\hline Masterton & 8 & 26 & 79 & 240 \\
\hline Wellington/Hutt Valley & 6 & 21 & 67 & 220 \\
\hline Nelson & 5 & 16 & 56 & 200 \\
\hline Blenheim & 5 & 17 & 58 & 210 \\
\hline Westport & 8 & 26 & 91 & 330 \\
\hline Kaikoura & 6 & 20 & 70 & 250 \\
\hline Greymouth & 10 & 34 & 110 & 410 \\
\hline Christchurch & 14 & 48 & 160 & 600 \\
\hline Mt Cook & 14 & 48 & 170 & 600 \\
\hline Timaru & 25 & 88 & 310 & 1200 \\
\hline Milford Sound & 12 & 62 & 330 & 1800 \\
\hline Queenstown & 12 & 54 & 250 & 1100 \\
\hline Oamaru & 27 & 100 & 380 & 1600 \\
\hline Dunedin & 31 & 130 & 500 & 2200 \\
\hline Invercargill & 14 & 50 & 170 & 650 \\
\hline
\end{tabular}

TABLE 3 : Mean return periods (years) for various intensities at selected locations. 